\title{
Drain Mast Komponentinin Tahribatsız Muayene Yöntemleri Kullanılarak Test Edilmesi
}

\author{
Cevahir Tarhan ${ }^{1}$, Berces Kurt ${ }^{2 *}$ \\ ${ }^{1}$ Erciyes Üniversitesi, Havacılık ve Uzay Bilimleri Fakültesi, Uçak Gövde ve Motor Bakımı Bölümü, Kayseri, Türkiye (ORCID: 0000-0002-4762-6719), \\ ctarhan@erciyes.edu.tr \\ 2*Erciyes Üniversitesi, Havacılık ve Uzay Bilimleri Fakültesi, Uçak Gövde ve Motor Bakımı Bölümü, Kayseri, Türkiye (ORCID: 0000-0002-1285-0542), \\ brcs_krt@hotmail.com \\ (İlk Geliş Tarihi: 08 Mayıs 2021 ve Kabul Tarihi: 25 Aralık 2021)
}

(DOI: $10.31590 /$ ejosat.934787)

ATIF/REFERENCE: Tarhan, C. \& Kurt, B. (2021). Drain Mast Komponentinin Tahribatsız Muayene Yöntemleri Kullanılarak Test Edilmesi. Avrupa Bilim ve Teknoloji Dergisi, (31), 852-860.

$\ddot{O} z$

Uçaklar servise verildikten sonra, farklı çalışma koşullarına ve birçok gerilime maruz kalır. Bu nedenle uçaklarda kullanılması için mukavemeti yüksek ve esneyebilen malzemeler seçilir. Ayrıca malzemelerin yüksek çekme ve basma dayanımı, korozyon direnci gibi özellikleri de göz önünde bulundurulur. Bir uçağın bakımı, uçağın üretim sürecinden itibaren başlar ve uçağın kullanıldığı son tarihe kadar yapılır. Bu bakımların amacı uçağın ve uçak komponentlerinin yapısal ve fonksiyonel performanslarını ilk günkü gibi korumaktır. Uçağın ve uçak komponentlerinin düzenli bakımları yapılmalıdır. Halihazırda kullanılan tahribatlı testler ile çok küçük çatlaklar tespit edilememektedir. Ayrıca bu yöntemler malzeme yapısına zarar verebilir. Bu olumsuzlukların üstesinden gelebilmek için tahribatsız muayene yöntemleri kullanılmaktadır. Tahribatsız muayene bilimi, malzeme kontrollerinin öncesinde ve sonrasında farklı teknik işlemler kullanılarak gerçekleştirilen çalışma alanıdır. Tahribatsız muayene medikal, polimer sektörü, havacılık alanı gibi geniş alanlarda kullanılmaktadır. Bu yöntemler sayesinde, sistemlerin ve malzemelerin özellikleri etkilenmeden kontrolleri yapılabilmektedir. Ayrıca tahribatsız muayeneler ile uçak bakımında darbe hasarı tespit edilebilir ve onarım veya sadece hata izleme şeklinde kararlar alınabilir. Bu çalışmada bir uçak komponentinin sıvı penetrant, gözle kontrol (boroskop, büyüteç, fener, ayna, komparatör vb.) ve ultrasonik kontrol yöntemleri ile kontrolleri yapıldı. Bu yöntemler kullanılarak test numunesinin üzerindeki hata ve kusurlar tespit edildi. Bu testler yapılırken ele alınan uçak komponentinin zarar görmemesi ve doğru sonuçlar elde edilebilmesi için en uygun muayene yöntemi belirlendi ve ilgili yöntemlerin kullanım açısından mukayesesi yapıldı.

Anahtar Kelimeler: Tahribatsız muayene, Hava-Uzay araçları tasarımı ve malzemesi, Kompozit malzemeler, Ölçme Tekniği, Ultrasonik control.

\section{Testing of Drain Mast Component Using Non-Destructive Testing Methods}

\begin{abstract}
After the aircraft are put into service, they are subjected to different operating conditions and many stresses. For this reason, materials with high strength and flexibility are selected for use in airplanes. In addition, the properties of the materials such as high tensile and compression strength, corrosion resistance are also taken into consideration. Maintenance of an aircraft starts from the production process of the aircraft and is done until the last date the aircraft is used. The purpose of these maintenance is to preserve the structural and functional performance of the aircraft and aircraft components as on the first day. Regular maintenance of the aircraft and aircraft components should be carried out. Very small cracks cannot be detected with the destructive tests currently used. In addition, these methods can damage the material structure. Non-destructive testing methods are used to overcome these negativities. Non-destructive testing science is a field of study performed using different technical processes before and after material controls. Non-destructive testing is used in wide areas such as medical, polymer industry, aviation field. Thanks to these methods, controls can be made without affecting the properties of systems and materials. In addition, with non-destructive inspections, impact damage can be detected in aircraft maintenance and decisions can be made in the form of repair or just defect tracking. In this study, an aircraft component was controlled by liquid penetrant, visual inspection (borescope, magnifier, flashlight, mirror, comparator etc.) and ultrasonic control methods. Using these methods, defects on the test sample were detected. While performing these tests, the most appropriate inspection method was determined in order not to damage the aircraft component and to obtain accurate results, and the related methods were compared in terms of usage.
\end{abstract}

Keywords: Non-destructive testing, Air-Spacecraft design and material, Composite materials, Measurement technique, Ultrasonic control.

*Sorumlu Yazar: brcs_krt@hotmail.com 


\section{Giriş}

Tahribatlı test yöntemlerinde, malzemelere eğilme, çekme, burkulma, kesme gibi kuvvetler uygulandığından dolayı, test edilecek malzemeler zarar görebilir (Başyiğit ve ark., 2013). Bu tür testlerden dolayı malzeme işlevselliğini kaybedebilir (Türker ve ark., 2011). Bu yüzden malzemelerin testi yapılırken tahribatlı muayene yöntemleri yerine tahribatsız muayene yöntemleri tercih edilmektedir. Tahribatsız muayene yöntemleri sayesinde, test edilecek malzemelerin hasar görmeden veya test edilecek malzemelerin yapısını değiştirmeden, malzemelerin yüzeyindeki ve iç yapısındaki hasarlar veya süreksizlikler tespit edilebilmektedir (Dwivedi et al., 2018; Üllen ve Baba, 2020; Gholizadeh, 2016). Tahribatsı muayene medikal, polimer sektörü, havacılık alanı gibi geniş alanlarda kullanılmaktadır (Towsyfyan et al., 2020). Bu yöntemler özellikle havacılık alanında çok fazla kullanılmaktadır. Çünkü tahribatsız muayene yöntemleri, uçak yapıları için 'Uçuşa elverişlilik' gereksinimlerinin uygunluğunu izlemek için kullanılabilecek en uygun denetim ve değerlendirme imkanı sunar (Mahoon, 1988; Towsyfyan et al., 2020). Özellikle uçak malzemelerinin ve komponentlerinin sürekli gerilim yüklerine maruz kalmasıyla, bu muayene tekniklerinin önemi daha da artmaktadır (Diamanti ve Soutis, 2010; Gärtner et al., 2002). Tahribatsı muayene yöntemi, algılama ve nüfuziyet fonksiyonlarına dayanmaktadır (Seçim, 2011). Bu fonksiyonlardan, algılama fonksiyonu nüfuz ediciden aldığı bilgileri testi yapan kişinin anlayabileceği hale dönüştürür. Nüfuziyet işlevi ise nüfuz edici elemanının giriciliğini ve malzemelerdeki kusurları algılama elemanına gönderir (Seçim, 2011). Tahribatsız muayene yöntemleri, yüzeysel ve hacimsel olarak ikiye ayrilır. Ultrasonik ve radyografik kontrol yöntemleri hacimsel ve gözle kontrol, sıv1 penetrant, girdap akımları ve manyetik parçacık kontrolü yöntemleri ise yüzeysel yöntemlerdir. Yüzeysel yöntemlerde malzemenin tamamıma nüfus edilemez, sadece malzemenin yüzeyinde ve yüzeye yakın bölgelerindeki süreksizlikler tespit edilebilir (Kayrak, 2012). Hacimsel yöntemlerde ise malzemenin tamamına nüfus edilir ve malzemenin içindeki süreksizlikler de tespit edilebilir (Kayrak, 2012).

Tahribatsız muayene teknikleri hakkında literatürde oldukça fazla makale bulunmaktadır (Dwivedi et al., 2018; Üllen ve Baba, 2020; Gholizadeh, 2016; Towsyfyan et al., 2020; Seçim, 2011; Kayrak, 2012). Ancak yapılan bu incelemelerde, genellikle tek bir tahribatsız muayene tekniği değerlendirilmektedir. Ayrıca tahribatsız muayene teknikleri ile ilgili literatürde bulunan makalelerde, tahribatsız muayene yöntemlerinin kendi içinde kıyaslanmalarının olmaması, bu alanda daha çok çalışmaların yapılması gerekliliğini ortaya çıkarmaktadır. $\mathrm{Bu}$ bağlamda, bu çalışmada, bir uçak komponenti üzerinde çeşitli tahribatsız muayene teknikleri kullanıldı. Kullanılan bu yöntemlerin, hem kendi içerisinde hem de ayrı ayrı değerlendirilmeleri yapıldı. Ayrıca bu tekniklerin avantajları ve dezavantajları belirlendi. $\mathrm{Bu}$ inceleme sayesinde, kullanılan tahribatsız muayene teknikleri arasında, malzemelerde bulunan kusurların tespit edilebilmesinde kullanılabilecek en uygun muayene yönteminin belirlenebilmesi amaçlanmıştır.

Tahribatsız muayene yöntemlerinden, en önemlisi görsel inceleme yöntemidir. Çünkü bütün tahribatsız muayene tekniklerinde, görsel inceleme de gerçekleştirilmektedir. Melloy ve ark. (2000) çalışmalarında, görsel incelemenin uçaklarda yapılan testlerin \%90'ını oluşturduğunu belirtmiş̧lerdir. Bossi ve
Giurgiutiu (2015) çalışmalarında, gözle muayene yönteminin uçakların farklı kompozit yapıları için en önemli inceleme yöntemi olduğunu belirtmişlerdir. Goranson (1983), çalışmasında, 1983 yılında büyük nakliye uçaklarında yapılan muayenelerin \%80'inden fazlasının görsel yöntemlere dayandığını belirtmektedir. Drury ve Watson (2002) ise 2002 yılında büyük nakliye uçaklarında yapılan muayenelerin, \%54'ünün görsel muayene ile yapıldığını belirtmişlerdir. Uçaklarda yapılan görsel muayenenin önemi oldukça büyüktür çünkü uçaktaki kusur ve süreksizliklerin ilk tespiti görsel muayene ile yapılmaktadır. Uçak komponentleri üzerindeki çatlaklar, korozyon, gevşek bağlantı elemanları, aşınma, eksik parçalar, hatalar, süreksizlikler, pullanma, deleminasyon gibi kusurlar gözle tespit edilebilmektedir. Aynı zamanda görsel inceleme ile birleştirilmiş yapılarda ve bileşenlerdeki kusurlar bulunabilir. Ayrıca görsel inceleme, çatlakları veya yüzey çöküntülerini bulmanın en hızlı ve en ucuz yöntemi olarak kabul edilir (Fotouhi et al., 2021). Ancak görsel muayene yönteminin güvenirliliğini ve doğruluğunu etkileyen, incelenecek bölgedeki aydınlatma, kontrol süresi, testi yapan kişinin yorgunluğu ve deneyimi ve çevresel koşullar gibi faktörler vardır (Kujawińska ve Vogt, 2015; See, 2015). Eğer malzemenin iç yapısında bir kusur varsa, bu kusurun görsel inceleme ile tespit edilmesi olanaksızdır ve sınırlı erişime sahip bölgelerde görsel incelemenin yanlış yorumlanması da söz konusudur (Emerson et al., 1998). Bu yüzden görsel inceleme için yeni nesil teknolojilerden de yararlanılmaktadır. Novák ve ark. (2020) çalışmalarında, insansız hava araçlarının uçak bakım proseslerinde görsel muayene için kullanılabileceğini belirtmişlerdir. Matzkanin (2006) çalışmasında görsel inceleme ile yardımcı optik aletlerin de kullanıldığını da belirtmiştir. Çünkü sağlıklı bir insan gözünün ayırt edebileceği minimum kusur boyutu yaklaşık 0,25 inch olduğundan dolay1, bu limitin altındaki kusurlar çıplak gözle tespit edilememektedir. Ayrıca Papa ve Ponte (2018) çalışmalarında, geleneksel uçak muayene işlemleri ile uçakların görsel muayenesi, yapıldığında, çok zaman kaybedilebileceğini ve bunun yerine, görsel muayene yapılırken gelişmiş teknoloji yöntemlerinin (drone tabanlı uçak görsel muayene) kullanılmasıyla muayene sürelerinin azaltılabileceğini belirtmişlerdir.

Görsel inceleme, bütün tahribatsız muayene yöntemlerinden önce gerçekleştirilmesi gereken bir çalışmadır. $\mathrm{Bu}$ yöntem, hemen hemen bütün malzemelerin kontrol edilmesinde kullanılabilir (Gönül ve Bayraktaroğlu, 2015). Gözle kontrol işlemine başlamadan önce kontrol edilecek yüzeyler, uygun bir solvent ile mutlaka temizlenmelidir ve kontrol edilecek yüzeylerin gözle ulaşılabilir olması, iyi aydınlatılmış olması gereklidir. Görsel muayene yönteminde en çok kullanılan yardımcı elemanlar 'Şekil 1'de görülmektedir. 


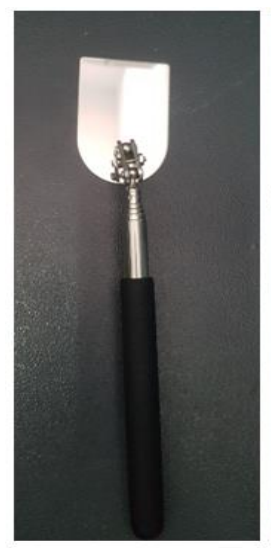

(a)

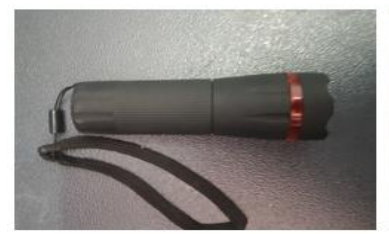

(d)

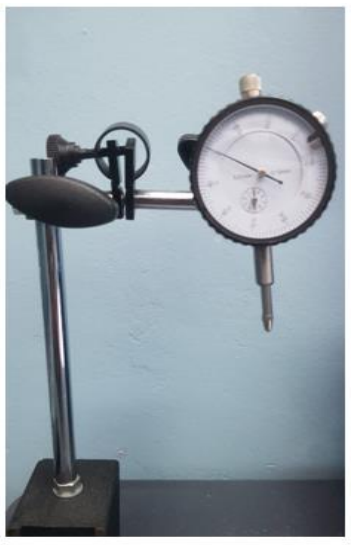

(b)

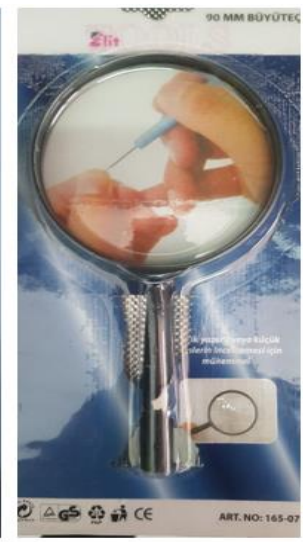

(c)

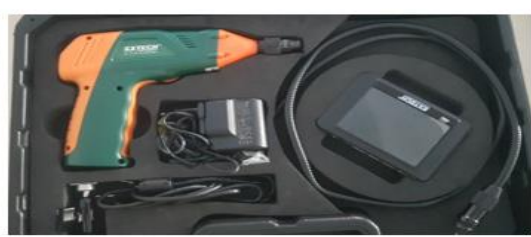

(e)

Şekil 1. Görsel muayene yönteminde kullanılan yardımcı elemanlar. ( a: Ayna, b: Komparatör, c: Büyüteç, d: Fener, e: Boroskop)

Tahribatsız muayene yöntemlerinden olan sıvı penetrant muayenesi de gözle muayene yöntemi gibi yüzeysel hata ve süreksizliklerin tespit edilmesinde kullanılmaktadır. Ancak sıvı penetrant muayene yöntemi ile malzemelerin iç yapısındaki kusurları tespit edilememektedir (Kılıç, 2019). Parida (2009) çalışmasında, penetrant muayenesinin temel prensibinin, yüzey gerilimi ve kılcal hareketin birleşik etkisiyle incelenecek temiz bir yüzeye penetrant uygulanıp, bir geliştirici tozunun etkisiyle ortaya çıkan kusurun içine sızması olduğunu belirtmiştir. Penetrant sıv1 kontrolünde penetrant ve test parça 1 sis1 $16^{\circ} \mathrm{C}-$ $52^{\circ} \mathrm{C}$ limitleri arasında olmalıdır (Kafalı, 2004). Bu muayene yönteminin etkinliği, kullanılan materyallerin boyutuna, parlaklığına ve kontrastına bağlıdır (Kalinichenko et al., 2019; Omelić ve Hrman, 2006). Bu yöntemin avantajlarından biri, diğer yöntemlere göre daha düşük maliyetli olmasıdır. Sıvı penetrant muayenesi metaller, cam, plastikler ve yanmış seramikler gibi gözeneksiz ve oldukça pürüzsüz malzemelerde hataların ve süreksizliklerin tespit edilmesi için başarıyla kullanılabilir (Taheri et al., 2019). Sıv1 penetrant yönteminde, yüzeyin pürüzsüz olması büyük önem arz etmektedir. Eğer malzeme yüzeyi pürüzlü ise sıvı penetrantın uygulanması oldukça zorlaşır ve hatalı sonuçlar almamıza neden olur (Migoun ve Delenkovsky, 2008). Bu hatalı sonuçlar, yüzey pürüzlülügüne sahip bir test yüzeyinden penetrant çıkarıldıktan sonra, penetrantın bazı kalıntı parçalarının yüzey mikro kusurlarının içinde kalması ve rahatsız edici bir arka plan oluşturması olgusundan kaynaklanır (Migoun ve Delenkovsky, 2008). Bu yöntemde öncelikle test edilecek malzemenin yüzeyi, uygun bir solvent ile temizlenir. Temizleme işlemi bittikten sonra malzemenin üzerine sivı penetrant uygulanır. S1vı penetrant uygulandıktan sonra belli bir süre (5-30 dakika) beklenir. $\mathrm{Bu}$ bekleme süresi içinde, penetrant malzeme üzerindeki çatlaklara nüfuz eder. Bu bekleme süresinden sonra uygun bir şekilde, malzeme üzerindeki fazla penetrant temizlenir. Temizleme işlemi yapılırken, malzemedeki çukurlara nüfuz eden penetrantın kaldırılmamasına dikkat edilir. Malzeme üzerindeki fazla penetrant uzaklaştırıldıktan sonra, malzeme üzerine bir geliştirici (spray) püskürtülür. Geliştiricinin uygulanmasından sonra da bir süre beklemek gerekmektedir. $\mathrm{Bu}$ bekleme süresinden sonra da malzeme üzerine püskürtülen developer beyaz bir tabaka oluşturur ve malzemenin çatlak bölgelerine nüfuz eden penetrant yüzeye çıkar. Böylece malzeme yüzeyindeki hata ve süreksizlikler kırmızı bir renkte görülmeye başlar (Manikandan et al., 2020) Bu işlemlerden sonra da test edilen malzemenin görsel kontrolü yapılır ve elde edilen bulgular not edilir (Suhaila et al., 2014). Siv1 penetrant yönteminde kullanılan malzemeler 'Şekil 2'de görülmektedir.

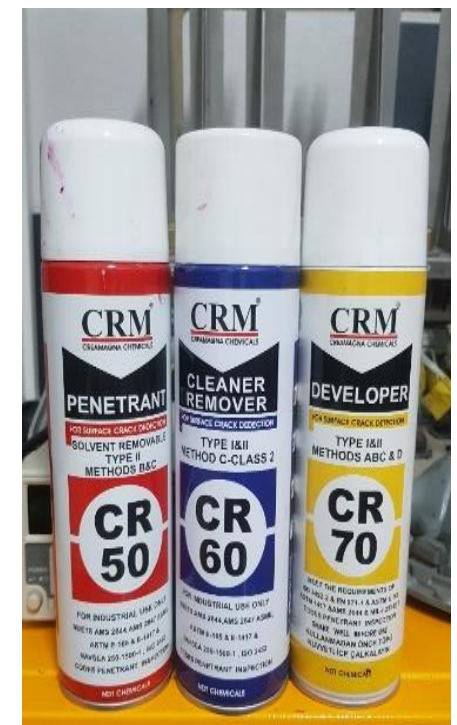

Şekil 2. Sıvı penetrant yönteminde kullanılan malzemeler.

S1vı penetrant yöntemi uçak komponentleri ve malzemeleri üzerinde de oldukça etkilidir. Guirong ve ark. (2015) çalışmalarında, sıvı penetrant testinin helikopter ve uçak bileşenleri için etkili bir tahribatsız muayene yöntemi olduğunu belirtmişlerdir. Taşınabilir penetrant malzemeler, furça veya silme uygulaması için küçük kaplarda 'Aerosol sprey kutularında' mevcuttur (Stancu ve ark., 2011). Bu aerosol kutu ile uçağın yapısına monte edilmiş parçalar üzerinde penetrant testi yapılabilmektedir (Stancu ve ark., 2011). Sezgin ve ark. (2017), çalışmalarında uçakların üretiminde ve bakımında yüksek güvenilirlik sağlamak için yaygın olarak sıvı penetrant testinin kullanıldığını ve bu yöntemin, esneklik ve kullanım kolaylığı gibi avantajlara sahip olduğunu belirtmişlerdir. Duarte ve ark. (2016) çalışmalarında, 'Portekiz Hava Kuvvetleri'nde tahribatsız yöntemler ile arıza analizinin uçuş güvenliğine nasıl katkıda bulunduğuna dair araştırma yapmışlardır. Bu araştırmada, filodaki 6 uçağın tamamını floresan sıvı penetrant muayene yöntemi ile incelenmişler ve 24 esnek noktanın tamamında $70 \mathrm{~mm}$ uzunluğa ulaşan çatlaklar olduğunu tespit etmişlerdir.

Girdap akımları ile muayene yöntemi, Faraday 'in elektromanyetik indüksiyonu keşfetmesiyle başlamıştır. 1879 yılında, bir bobinin farklı iletkenlik ve geçirgenlik değerlerine sahip metallerle temas ettiğinde, özelliklerinde değişiklikler olduğunu tespit edilmiştir (Chauveau, 2018). 1950 yılından itibaren, özellikle uçak ve nükleer endüstrilerinde girdap akımları ile ilgili çalışmalar yapılmıştır. Elektrik iletkenlik özelliğine sahip malzemelerde, zamanla değişen bir manyetik alan tarafından indüklenen akımlar girdap akımları olarak adlandırılır. Bu akımlar, fren sistemlerinde, enerjinin dağıtılması için ve dönen şaftların yavaşlatılması için veya 1sı kaynağ olarak kullanılabilmektedir (Aoukili ve Khamlichi, 2018). Ama transformatörlerde ve elektrik motorlarında kullanıldığında, 
enerji kaybına yol açmaktadırlar. Bu yöntem ile malzemelerdeki hata ve süreksizliklerin tahribatsı muayenesini de yapılabilmektedir (Aoukili ve Khamlichi, 2018). Bu tahribatsız muayene yönteminin çalışma prensibi, bir kaynak yardımı ile oluşturulan değişken manyetik alanın, test numunesinin yüzeyinde ve yüzeyine yakın olan kısımlarında girdap akımlarının endüklemesine dayanmaktadır (Durmuş ve Baygut, 2018). Eğer test edilen malzeme üzerinde herhangi bir süreksizlik veya hata varsa oluşan girdap akımları farklı bir yörünge izleyeceklerdir. Bu sayede, malzeme yüzeyindeki hata ve süreksizlikler belirlenmiş olur (Durmuş ve Baygut, 2018). Bu yöntemin aşamaları, sinyal oluşturma, test numunesi ile etkileşim, sinyal algılama, sinyalin işlenmesi ve sinyalin yansıtılması adımlarından oluşmaktadır. Girdap akımları kontrolünde, malzeme ile temas edilmesine ve malzeme yüzeyinin temizlenmesine gerek yoktur. Girdap akımları testi yüksek sicaklık $\left(\sim 1100^{\circ} \mathrm{C}\right)$ uygulamalarında kullanılabilir olmasından dolayı, uçak endüstrisinde, parçanın sertliğini ve gerilme mukavemetini ölçmek için ısıl işlem görmüş alüminyum bileşenlerin iletkenliğini ölçmek için kullanılabilir (Günay, 2018). Bu sayede, ölçümler ısıl işlem sırasında alınabilir ve proses hakkında daha fazla bilgi elde edilebilir. Ayrıca bu yöntem sayesinde malzemede bulunan korozyon, çatlak gibi kusurlar bulunabilirken, aynı zamanda iletken malzemelerde iletkenlik değerleri ve kaplamaların kalınlıkları ölçülebilmektedir (Gül, 2019). Girdap akımları yöntemi, sıvı penetrant, ultrasonik ve manyetik parçacık yöntemlerine göre daha hızlı değerlendirme imkanı sağlamaktadır. Ama girdap akımları ile muayene yönteminin bazı kısıtlamaları vardır. Bu yöntem, sadece elektrik iletkenliğine sahip malzemelerde kullanılabilmektedir ve çok yüksek hassasiyet gerektirmektedir. Ayrıca bu yöntem ile malzemenin iç yapısı kontrol edilememektedir ( $\mathrm{Lu}$ ve Wong, 2017). Girdap akımı yöntemi ile muayene, $6 \mathrm{~mm}$ 'den daha ince iletken parçaları yeterli hassasiyetle incelemek için kullanılabilir (Ippolito et al., 1995). Girdap akımı yöntemi, sadece elektrik iletkenliğine sahip malzemeler üzerinde kullanılabildiği için, biyomalzemeler, polimerik ve seramik malzemelerden imal edilen parçalarda kullanılamamaktadır. Girdap akımları yönteminin, katmanlı olarak üretilen bileşenlerde de olumlu sonuçlar vermesi beklenmektedir. Ancak katmanlı parçalar üzerindeki girdap akımı testinin etkinliği ve doğruluğu, parçanın yüzey kalitesi ve pürüzlülüğü girdap akımının akışında istenmeyen bozulmaya neden olacağından azalabilir. Katmanlı parçalar 1,6-25 $\mu \mathrm{m}$ aralığında yüzey pürüzlülüğüne sahipken, kalıp döküm ile üretilen parçalar 3,2 ve $6,4 \mu \mathrm{m}$ ve sicak dövme ile üretilen parçalar 6,4 ve $13 \mu \mathrm{m}$ değerlerine sahiptir (Ippolito et al., 1995). Katmanlı parçalarda daha doğru sonuçlar alınabilmesi için girdap akımları yöntemi, diğer yöntemlerle beraber kullanılabilir (Grimm et al., 2015).

Ultrasonik kontrol yöntemi, endüstriyel malzemelerin ve komponentlerin test edilmesinde kullanılan en iyi tahribatsız muayene yöntemlerinden biridir (Fathi-Haftshejani ve Honarvar, 2019; Habibpour-Ledari ve Honarvar, 2018; Shakibi et al., 2012). Çoğu tahribatsız muayene yönteminde, test edilecek malzemenin kalınlığı sınırlayıcı bir faktördür. Ancak ultrasonik kontrol tekniği ile birkaç metre derinde bulunan kusurlar bile tespit edilebilmektedir (Cerniglia et al., 2015). Ultrasonik kontrol yöntemi, diğer tahribatsız muayene yöntemlerine göre daha fazla önem arz etmektedir. Çünkü ultrasonik kontrol yönteminin, güçlü penetrasyon, yüksek hassasiyet ve insan vücuduna zarar vermemesi gibi avantajları vardır (Ma et al., 2002). Ayrıca ultrasonik muayene yöntemi ile hem metal hem de metal olmayan malzemelerin kontrolü yapılabilmektedir (Nesvijski, 2000; Prassianakis ve Prassianakis, 2004). Ultrasonik kontrol yöntemi havacılık, kimya, fizik, tıp, uzaklık ölçme gibi alanlarda kullanılmaktadır. Havacılık alanında metal ve kompozit parçalardaki kusurların tespit edilebilmesi için kullanılmaktadır (Öktem, 2002). Mouritz ve ark. (2000) çalışmalarında, uçak yapılarında kullanılan karbon fiber takviyeli epoksi kompozitlerde yorgunluk hasarını tespit etmek için ultrasonik kontrolünün yapıldığını belirtmişlerdir. $\mathrm{Bu}$ çalışmada A- tarama kayıtlarını incelediklerinde, malzemelerdeki eğilme ve kopma hasarlarını tespit etmişlerdir. Zorbacı (2011) çalışmasında, uçak kanat yapıları üzerindeki korozyonun tespit edilmesinde ultrasonik muayene yönteminin kullanıldığını belirtmiştir. $\mathrm{Bu}$ muayene sonucunda kanat yapılarında, gerilimli korozyon, çatlak korozyonu ve pullanma korozyonu tespit edilmiştir.

Hacimsel tahribatsız muayene yöntemlerinden biri olan ultrasonik kontrol yönteminde, periyot, frekans, dalga boyu gibi temel kavramlar vardır. Periyot, parçacığın hareketinin bir tam devrini tamamlaması için geçen süredir ve birimi süredir. Periyot değeri, ' $T$ ' ile gösterilir (Jewett ve Serway, 2008). Frekans ise parçacığın birim zamanda yaptığı salınım sayısını ifade eder. Frekansın birimi 'Hertz 'dir ve ' $F$ ' ile gösterilir (Jewett ve Serway, 2008). Dalga boyu ise aynı titreşim fazında bulunan komşu iki parçacık arasındaki mesafedir ve dalganın frekansına ve ilerleme hızına bağlıdır (Jewett ve Serway, 2008). Bu yöntem ile malzemelerin iç yapısındaki hata ve süreksizlikler tespit edilebilmektedir (Akay ve ark., 2013). Ultrasonik muayene yöntemi, yüksek frekanslı ses dalgalarıyla yapılan bir yöntemdir ve frekansı $20 \mathrm{kHz}$ 'den daha yüksek olan ses dalgaları, ultrasonik dalgalar olarak adlandırılır (Schmerr, 2016). Metallerin ultrasonik muayenesinde, genellikle $50 \mathrm{MHz}$ 'e kadar olan frekanslar kullanılabilmesine rağmen, 0,1-10 MHz arasında değişen frekanslara sahip kısa darbe dalgaları kullanılmaktadır (Schmerr, 2016). Ultrasonik dalgalar homojen olarak yansitılmadığı için, iletilen ve yansıtılan enerjilerin değerlendirilmesi malzemenin bütünlüğü ile ilişkilendirmek için kullanılabilir (Schmerr, 2016). Ultrasonik kontrol yöntemi, arıza tespitinde, boyutsal ölçümlerde ve malzemelerin karakterizasyonu belirlemede kullanılabilmektedir. $\mathrm{Bu}$ test yönteminde, bir prop ve bir ultrasonik test cihazı kullanılır. Ultrasonik test için prop seçimi, test numunesinin kalınlığına uygun frekans değerinde olmalıdır. Prob tarafindan iletilen ses dalgaları, test numunesine iletilir. Eğer test edilen materyalin iç yapısında bir süreksizlik veya hata tespit edilirse, ses dalgaları bu kusurların bulunduğu kısımdan geri yansır (Garcia ve Gomez, 2020). Yansiyan bu ses dalgası sinyali, prob tarafindan elektrik sinyaline dönüştürülür (Garcia ve Gomez, 2020). Ultrasonik testte kullanılan cihazın gösterge alanında, bu kusurların yeri ve boyutu görünür (Okan ve ark 2017). Ultrasonik muayene yöntemi ile girdap akımları yöntemi birlikte kullanılabilmektedir (Y1lmaz, 2014).

Manyetik parçacık ile yapılan tahribatsız muayene yönteminde test edilecek numunenin derinlemesine yüzey hazırlığına gerek yoktur ve bu yöntemin uygulanışı oldukça hızlıdır (Yağcı ve ark., 2018). Bu yöntem ile malzemelerin muayenesi yapılırken, manyetik partiküllerden ve manyetik alandan faydalanılır (Özkan, 2019). Bu yöntem ile test edilen malzemelerdeki hataların belirlenebilmesi, hatanın boyutuna ve yüzeye yakınlığına bağlıdır (Blitz, 2012). Ayrıca bu yöntemin uygulanabilmesi için test edilecek malzemelerin demir, nikel, kobalt gibi ferromanyetik özellikte olmaları gerekmektedir 
(Gönül ve Bayraktaroğlu, 2018). Manyetik kutup çiftine sahip malzemelerin manyetik alan içindeki davranışları farklı türlerde olur ve bu davranışlar da malzemelerin manyetiklik türünü belirler (Gövce, 2015). Manyetik parçacık ile muayene yöntemi özellikle çelik ve titanyum gibi malzemelerde etkili sonuçlar verir. $\mathrm{Bu}$ yöntem, malzemenin yüzeyindeki ve yüzeyine yakın kısımlarında bulunan korozyonunun, kusurun ve süreksizliğin tespitinde oldukça etkilidir (Gövce, 2015). Manyetik parçacık kontrolüne başlamadan önce bir düzenek yardımı ile malzeme mıknatıslandırılır. Mıknatıslanan bu malzemenin molekülleri üzerinde kuzey ve güney kutupları oluşur. Burada oluşan kuvvet çizgileri kuzey (north) kutbundan çıkar ve güney (south) kutbuna girer (Gönül ve Bayraktaroğlu, 2015). Bu şekilde devamlı ve daima kapalı bir çevrim gerçekleşir ve böylece bir manyetik alan oluşur. Manyetik alan oluştuktan sonra, test numunesinin yüzeyine demir tozu dökülür veya ince toz hâlinde manyetik malzeme püskürtülür. Manyetik parçacık ile muayene yönteminde, kusurların tespit edilebilmesi için genellikle demir tozu kullanılmaktadır. Miknatıslanan malzemenin üzerine dökülen demir tozları manyetik alanda akı kuvvet çizgileri boyunca sıralı hale gelir. Eğer test edilen malzemede bir kusur varsa demir tozlar hatanın bulunduğu yerde birikir (Gönül ve Bayraktaroğlu, 2015). Bu yöntem, test numunesinin boyutu ve şekli üzerinde neredeyse hiçbir kısıtlama olmaksızın, çok sı̆̆ ve ince çatlaklar gibi yüzey süreksizliklerini tespit etmek için kullanılan en güvenilir tekniktir (Shull, 2002). Ancak bu muayene yönteminin kullanılmasını kısıtlayan, sadece mıknatıslanabilen malzemelere uygulanabilmesi, malzemelerin iç yapısının kontrol edilememesi gibi faktörler vardır (Yetiştiren ve ark., 2007).

Tahribatsız muayene yöntemleri yüzeysel ve hacimsel olarak ayrıldığında, radyografik muayene ve ultrasonik muayene yöntemleri, hacimsel yöntemler sinıfına girer. Radyografik kontrol yönteminde, yüksek enerjiye sahip elektromanyetik dalgalar pek çok malzemeye nüfuz edebilir (Robini et al., 2006). $\mathrm{Bu}$ dalgalar, malzemenin farklı kısmına yerleştirilen dalgaya duyarlı filmleri de etkileyebilir (Tuğrul ve ark., 2008). Filmlerin banyo işlemi gerçekleştirildiğinde test numunesi yapısının görüntüsü elde edilir. Bu görüntü malzeme içindeki boşluklardan dolayı ya da malzemenin yoğunluk ve kalınlık değişkenlerinden dolayı ortaya çıkar (Robini et al., 2006). Malzemelerin iç yapısını bu şekilde görüntülemek için kullanılan yönteme radyografi yöntemi denir (Tuğrul ve ark., 2008). Radyografik kontrol yöntemi, diğer tahribatsız muayene yöntemlerine göre, test edilen malzemelerin türü üzerinde herhangi bir kısıtlama olmaksızın, önemli bir avantajı vardır. Bu yöntem ile yoğunluk, kalınlık ölçümü gibi malzemenin temel yapısı hakkında bilgiler elde edilebilir (Shull, 2002). Ancak bu yöntemin kullanımı kısıtlayan birçok etken vardır. $\mathrm{Bu}$ yöntemde elde edilen sonuçların analizi ve yorumlanması oldukça deneyimli uzmanlar tarafindan yapılmalıdır. Radyografi yöntemde radyasyon tehlikesi olduğundan dolayı gerekli güvenlik önlemleri alınmalıdır. Ayrıca bu yöntemde malzemeye gömülü olan çatlaklar tespit edilememektir çünkü çatlak radyasyonun hareket yönüne paralel olmalı veya radyografiye kaydedilmesi için yeterince büyük olmalıdır (Raj et al., 2002). Radyografik kontrol yöntemi, malzemelerin iç yapısındaki hata ve süreksizliklerin tespit edilebilmesi en çok kullanılan tahribatsız muayenelerden biridir. Ama bu muayene doğru bir şekilde yapılmalıdır yoksa verimli sonuçlar alınamaz (Gürsel, 2013). X 1şınları veya gama 1şınları, bu muayene yönteminin en önemli teknikleridir. Işınlama enerjisini etkileyen faktörler, görüntünün yansıtılacağ filmin mesafesi, malzemenin tipi, ışın kaynağının malzemeye e-ISSN: 2148-2683 uzaklığı, malzeme kalınlığı gibi etkenlerdir (Raj et al., 2002). Muayene sonucunda doğru sonuçlar elde etmek için, testler standartlara uygun olarak yapılmalıdır. Radyografik testler genellikle EN 1435 veya EN 12517 standartlarına göre yapılır alınamaz (Gürsel, 2013). Bu yöntem, tıp, demiryolu, endüstriyel uygulamalar ve havacılık gibi çok geniş alanlarda kullanılabilmektedir. Havacılıkta, uçak malzemeleri ve ekipmanları üzerinde kullanılmaktadır. Uçakların kompozit yapılarındaki su, nem, yapıştırıcı bozulmalar, yorulma çatlakları, ezilmeler, petekteki ayrılmalar ve yüzey malzemelerinde oluşan süreksizlikler radyografik yöntem ile kolayca bulunabilmektedir (Kayrak, 2012). Muayene işlem süresinin kısa olması, geniş aralıkların kontrol edilebilmesi, test sonuçlarının kalıcı olması ve doğru sonuçlar elde edilebilmesinden dolayı bu yöntem yaygın olarak kullanılmaktadır (Kayrak, 2012; Üner, 2011). Üner (2011) çalışmasında, radyografik kontrolün havacılıkta, makro yapıların incelenmesinde, çatlak, korozyon, gevrek bağlantı parçaların ve perçinlerin, hasarlı yapıların, karmaşık yapı arızalarının veya aksaklıklarının tespit edilmesinde, bal peteği kompozit yapıların tetkikinde ve tüm malzemelerdeki kaynak kontrolü için kullanılabileceğini belirtmiştir. Kafalı (2004) ise çalışmasında, bir Boeing 737-800 tipi uçağın flap ucunda bulunan petek yapının, radyografik yöntem ile kontrol edildiğini belirtmiştir. $\mathrm{Bu}$ yöntem sayesinde, petek yapısının içindeki su ve yapıştırıcı birikintileri ve yapının içindeki su birikintileri tespit edilmiştir.

\section{Deneysel Çalışmalar}

Bu bölümde, 'Drain Mast' komponentinin gözle kontrol (boroskop), sıvı penetrant ve ultrasonik kontrol yöntemleri ile tahribatsız muayenesi yapılmıştır. Gözle kontrol ve sıv1 penetrant yöntemleri ile test numunesinin yüzeysel kontrolleri, ultrasonik kontrol yöntemi ile de test malzemesinin hacimsel kontrolleri yapılmıştır ve testlerde doğru sonuçların alınabilmesi için test numunelerinin ön temizliği yapılmıştır.

\subsection{Drain Mast Komponentinin Görsel Muayenesi}

Airbus uçağına ait ve 'PN: 4-6000H883-00' numaralı 'Drain mast' komponentinin önce ön temizlik işlemi gerçekleştirilmiştir. Temizlik işleminden sonra ise büyüteç, komparatör gibi yardımcı elemanlar kullanılarak komponentin görsel incelemesi yapılmıştır. Drain mast komponentinin direkt olarak erişilemeyen bölgelerinin kontrolü, boroskop cihazı ile gerçekleştirildi. Boroskop ile gerçekleştirilen inceleme 'Şekil 3 'te görülmektedir.

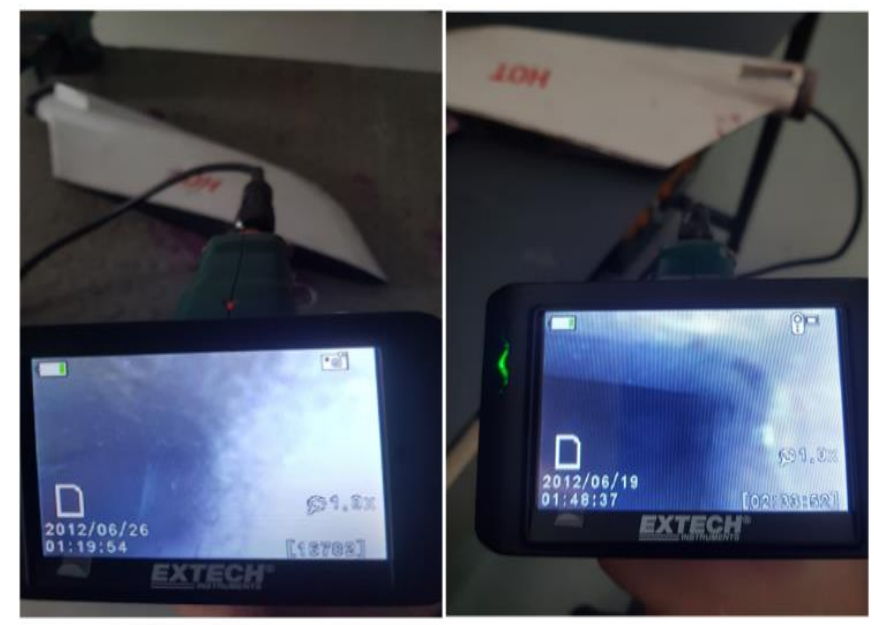

Şekil 3. Drain Mast komponentinin boroskop cihazı ile incelenmesi. 
Drain mast komponentinin yüzeysel muayenesi sırasında elde edilen görüntüler, daha sonradan da kontrol edilebilmesi için boroskop cihazı aracılığıyla kaydedilmiştir. Boroskop cihazı ile kaydedilen görüntüler 'Şekil 4'te görülmektedir.
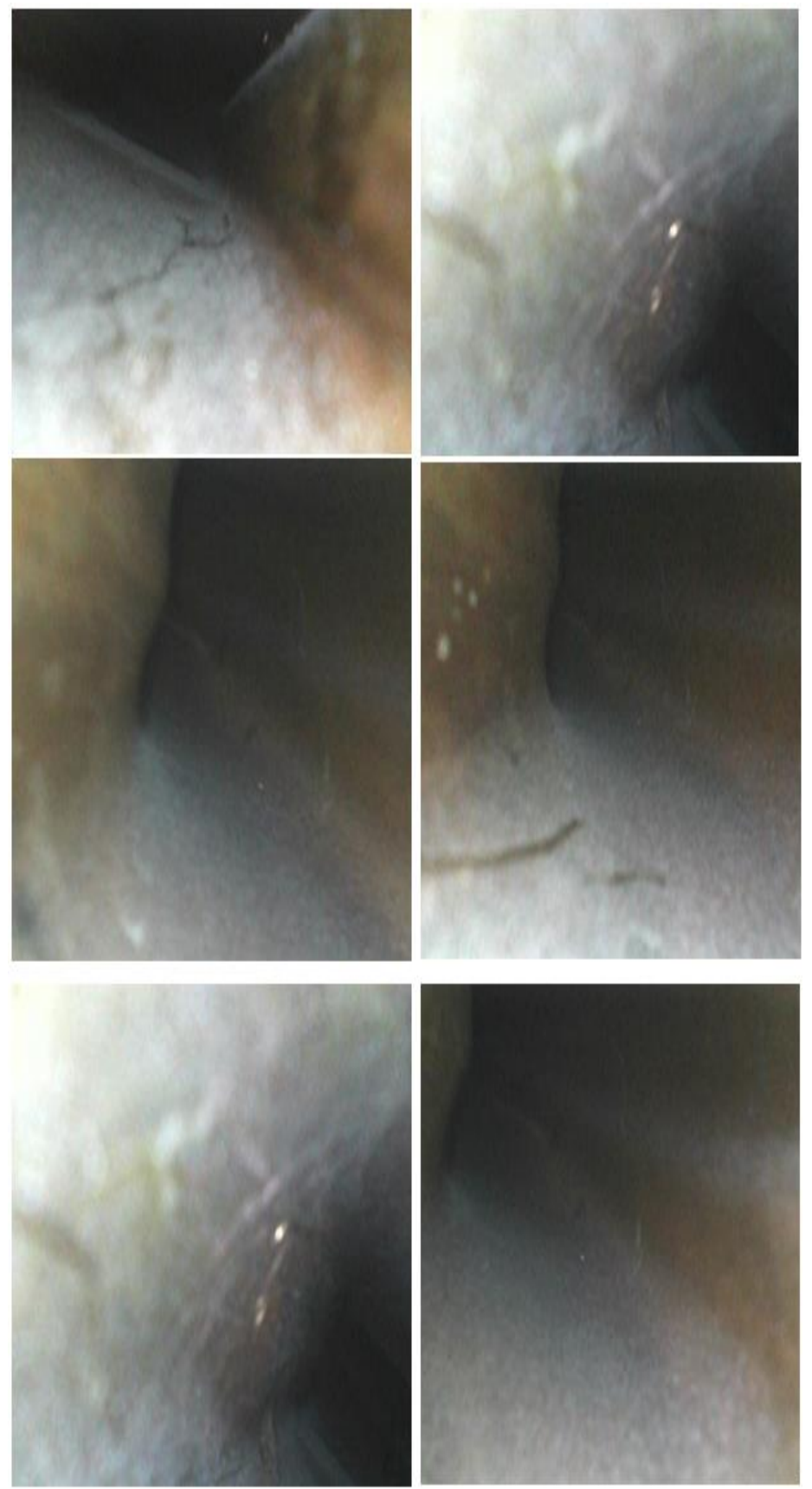

Şekil 4. Drain mast komponentinin boroskop cihazı ile incelemesinde elde edilen görüntüler.

Şekil 4'te görüldüğg̈ üzere drain mast komponentinin iç yüzeyinde nokta şeklinde çukurcuklar, aşınmalar ve çizikler oluştuğu görülmektedir. Ama bu kusurların iç bölgede çatlak oluşturacak seviyede olmadığı tespit edilmiştir çünkü yapılan kontrollerde herhangi bir çatlak izine rastlanmamıştır.

\subsection{Drain Mast Komponentinin Sivı Penetrant Muayenesi}

Airbus uçağına ait ve 'PN: 4-6000H883-00' numaralı 'Drain mast' komponenti, öncelikle uygun çözücü kullanılarak temizlenmiştir. $\mathrm{Bu}$ işlemden sonra komponentin yüzeyine, $\mathrm{CR}$ 50 (penetrant) spreyi sıkılmıştır. Uygun bekleme süresinden sonra komponent üzerindeki fazla penetrant, CR 60 (cleaner) solventi kullanılarak uzaklaştırılmış̧ır. Son aşama olarak da CR 70 (developer) spreyi sikılarak, komponent üzerinde beyaz bir tabaka oluşturulmuştur. Drain mast komponentinin penetrant uygulaması 'Şekil 5'te görülmektedir.

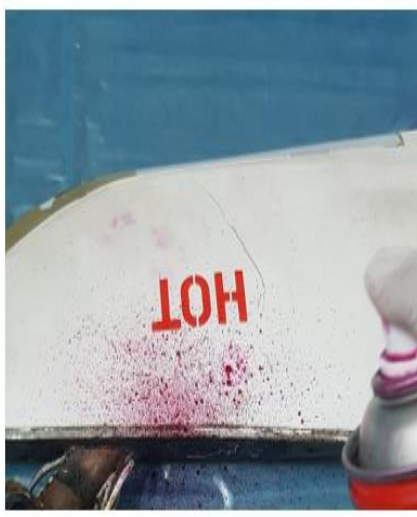

(a)

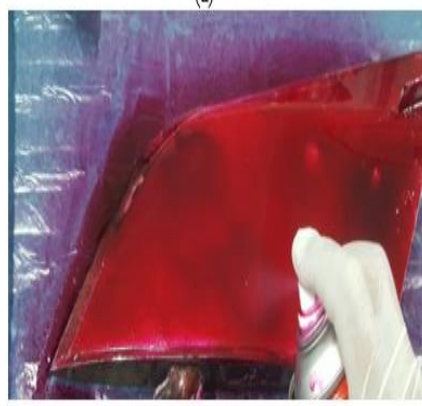

(c)

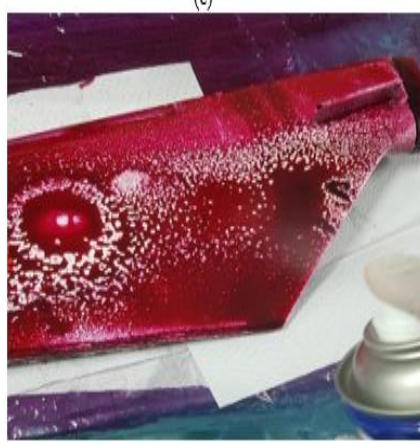

(e)

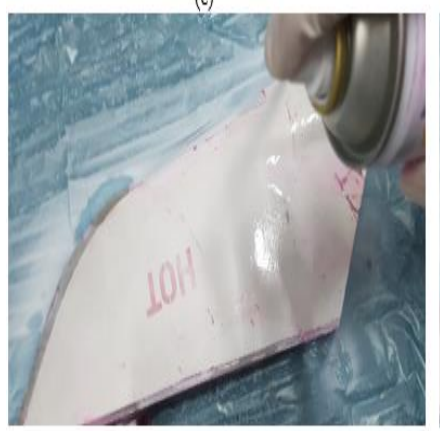

(g)

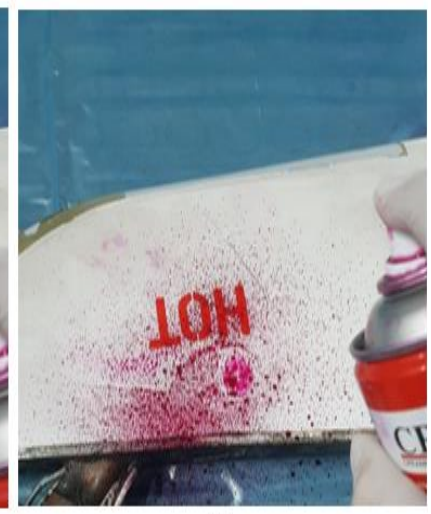

(b)

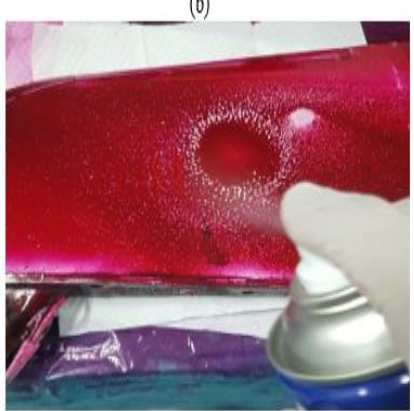

(d)

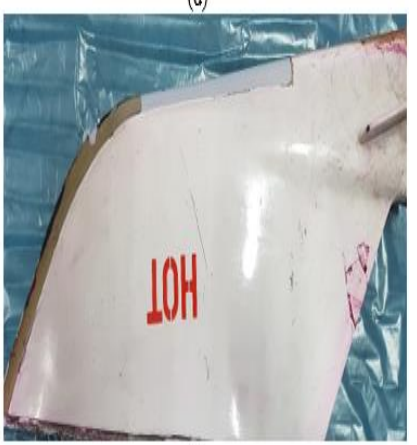

(f)

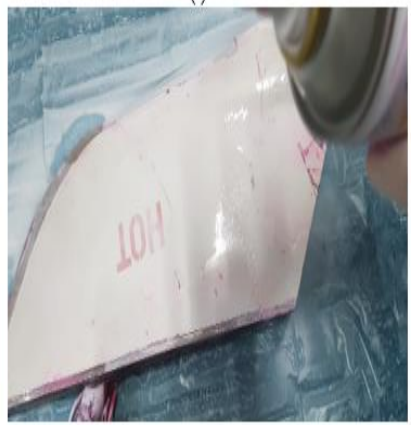

(h)
Şekil 5. Drain mast komponentinin penetrant uygulaması.

Yukarıda 'a, b ve c' aşamalarında görüldüğü üzere öncelikle drain mast komponenti üzerine penetrant uygulanmıştır. Belli bir süre bekledikten sonra ' $d$, e ve $\mathrm{f}$ ' aşamalarında görüldüğü gibi fazla penetrantın alınabilmesi için cleaner uygulanmışırı. Fazla penetrant alındıktan sonra ' $\mathrm{g}$ ve h' aşamalarında görüldüğü üzere developer uygulanmıştır ve belli bir süre beklenmiştir. $\mathrm{Bu}$ uygulamadan sonra, daha net bir şekilde görülen yüzeysel kusurlar 'Şekil 6'da görülmektedir. 

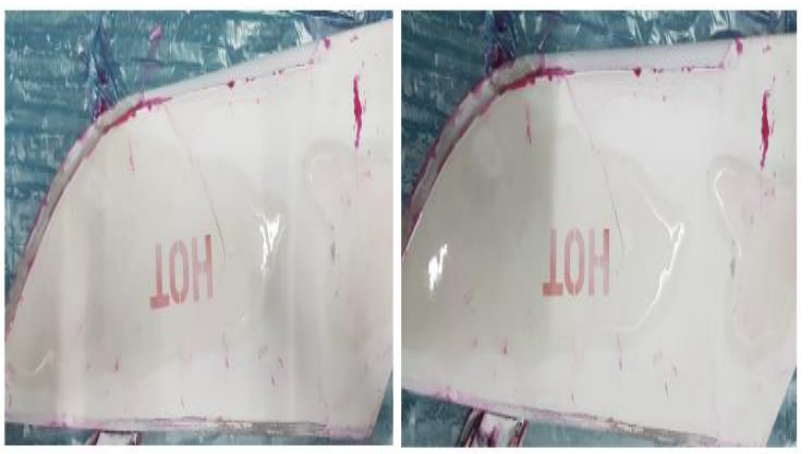

Şekil 6. Drain mast komponentinin penetrant uygulaması ile muayenesi.

Şekil 6'da görüldüğü üzere drain mast komponentinin dış yüzeyinde developer sayesinde bir beyaz tabaka oluşturulmuştur. Drain mast komponentin üzerindeki fazla penetrantın temizlendiği aşamada, komponentin üzerindeki çatlaklara nüfuz eden penetrant sıvısı uzaklaştırılmamıştır. Bu sayede beyaz tabaka oluşturulduğunda, kırmızı olarak görülen kısımlarda hata ve süreksizliklerin olduğu tespit edilmiştir.

\subsection{Drain Mast Komponentinin Ultrasonik Kontrolü}

Airbus uçağına ait ve 'PN: 4-6000H883-00' numaralı 'Drain mast' komponentinin ön temizlik işlemi tamamlandıktan sonra, kontrol edilecek yüzeye ultrasonik jel sürülmüştür. $\mathrm{Bu}$ kontrolde ' $2 \mathrm{Mhz}$ ve $0^{\circ}$ ' özelliklere sahip ultrasonik prob kullanılmıştır. Drain mast komponentinin ultrasonik muayenesi 'Şekil 7'de görülmektedir.

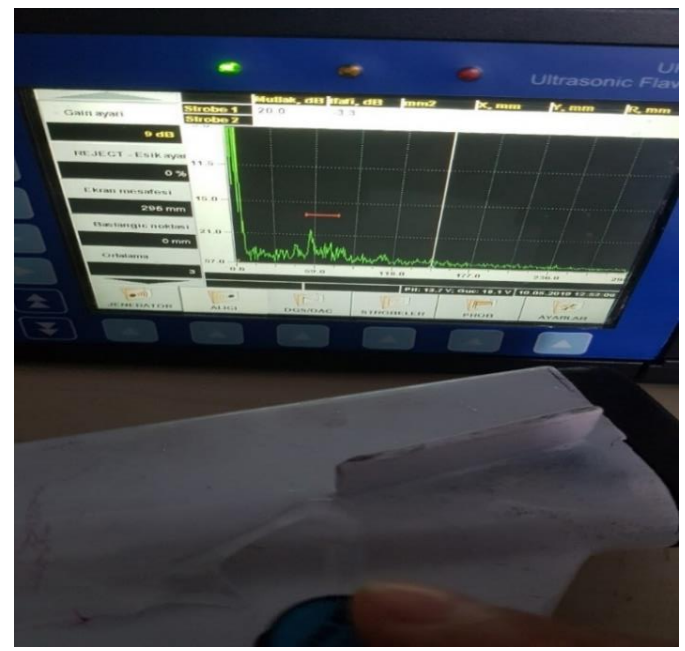

Şekil 7. Drain mast komponentinin ultrasonik kontrol ile muayenesi.

Şekil 7'de görülen drain mast komponentinin ultrasonik muayenesinde, 'Mutlak desibel' değeri '20.0 dB' ve 'Bağıl desibel' değeri ' $-3.3 \mathrm{~dB}$ ' olarak tespit edilmiştir. $\mathrm{Bu}$ komponentin ultrasonik kontrolleri sonucunda, iç yapısında herhangi bir hata veya süreksizlik tespit edilmemiştir.

\section{Sonuç ve Tartışma}

Drain mast, komponenti üzerinde gerçekleştirilen görsel muayene, siv1 penetrant ile muayene ve ultrasonik kontrol yöntemlerinin karşı1laştırılması 'Tablo 1'de görülmektedir.
Tablo 1. Görsel, sıv1 penetrant ve ultrasonik kontrol yöntemlerinin karşılaştırılması.

\begin{tabular}{|l|l|l|l|}
\hline & $\begin{array}{l}\text { Görsel } \\
\text { Muayene } \\
\text { (Boroskop) }\end{array}$ & $\begin{array}{l}\text { Sıvı } \\
\text { Penetrant } \\
\text { Yöntemi }\end{array}$ & $\begin{array}{l}\text { Ultrasonik } \\
\text { Kontrol }\end{array}$ \\
\hline İlk Maliyet & Orta & Ucuz & Yüksek \\
\hline $\begin{array}{l}\text { Kullanım } \\
\text { Maliyeti }\end{array}$ & Çok az & Orta & Çok az \\
\hline $\begin{array}{l}\text { Ekipmanların } \\
\text { Taşınabilirliği }\end{array}$ & Taşınabilir & Taşınabilir & Taşınabilir \\
\hline $\begin{array}{l}\text { Test } \\
\text { Numunesinin } \\
\text { Geometrik } \\
\text { Etkisi }\end{array}$ & $\begin{array}{l}\text { Önemli } \\
\text { değil }\end{array}$ & $\begin{array}{l}\text { O̧ok } \\
\text { değil }\end{array}$ & Önemli \\
\hline $\begin{array}{l}\text { Hassasiyet } \\
\text { Durumu }\end{array}$ & Az & Az & Yüksek \\
\hline Hata Türü & Yüzeysel & Yüzeysel & Hacimsel \\
\hline Test Süresi & 10-15 dk. & 30-45 dk. & 5-10 dk. \\
\hline Sonuç Süresi & Anında & Gecikmeli & Anında \\
\hline $\begin{array}{l}\text { Sonuçların } \\
\text { Edilebilmesi }\end{array}$ & Evet & Hayır & Hayır \\
\hline $\begin{array}{l}\text { Operatör } \\
\text { Tecribesi }\end{array}$ & Yüksek & Az & Yüksek \\
\hline
\end{tabular}

Tablo 1'e bakıldığında ultrasonik muayene yönteminin diğer yöntemlere göre daha pahalı olduğu anlaşılmaktadır. Ultrasonik kontrol ile hem hata tespitinin hem de kalınlık ölçümünün yapılabildiği görülmektedir. Bu yöntemlerde gerçekleştirilen test sonuçlarının sadece görsel muayene (boroskop) yönteminde kaydedilebildiği görülmektedir. Siv1 penetrant yönteminin uygulanabilmesi için testi yapan kişinin çok tecrübeli olmasına gerek yoktur.

Drain mast, komponenti üzerinde gerçekleştirilen deneysel çalışmalarda elde edilen sonuçlar aşağıda özetlenmiştir:

- Deneylerde elde edilen sonuçların, sadece görsel muayene (boroskop) yönteminde kaydedilebildiği belirlenmiştir.

- Deneylerde test edilen uçak komponentinin görsel muayenesinde ve sivı penetrant muayenesinde sadece yüzeydeki ve yüzeye yakın olan bölgelerdeki hata ve süreksizlikler tespit edilmiştir. Ultrasonik kontrolde ise malzemenin iç yapısındaki kusurların kontrolü yapılmıştır.

- Tahribatsız muayene yöntemleri, maliyet açısından karşılaştırıldığında, sıvı penetrant yönteminin en ucuz yöntem olduğu belirlenmiştir.

- Deneylerde kullanılan test numunelerinin geometrik etkisinin, görsel muayene ve sıvı penetrant muayenesinin sonuçlarını çok fazla etkilemediği tespit edilmiştir.

- Ultrasonik kontrol ve görsel muayene yöntemlerinde, test sonuçlarının anlık alınabildiği tespit edilmiştir. 


\section{Kaynakça}

Akay, A. A., Yakup, K. A. Y. A., \& Kahraman, N. (2013). Tozaltı Ark Kaynak Yöntemi İle Birleştirilen X60, X65 Ve X70 Çeliklerin Kaynak Bölgesinin Etüdü. Karaelmas Fen Ve Mühendislik Dergisi, 3(2), 34-42.

Aoukili, A., \& Khamlichi, A. (2018). Damage Detection Of Surface Cracks İn Metallic Parts By Pulsed Eddy-Current Probe. Procedia Manufacturing, 22, 209-214.

Başyiğit, C., Çomak, B., Kılınçarslan, Ş., \& Kamacı, Z. (2013). Depremde Hasar Görmüş Betonarme Yapıların Beton Kalitesini Belirlemede Yeni Yaklaşımlar: Görüntü İşleme Örneği.

Blitz, J. (2012). Electrical And Magnetic Methods Of NonDestructive Testing (Vol. 3). Springer Science \& Business Media.

Bossi, R. H., \& Giurgiutiu, V. (2015). Nondestructive Testing Of Damage İn Aerospace Composites. In Polymer Composites In The Aerospace Industry (Pp. 413-448). Woodhead Publishing.

Cerniglia, D., Scafidi, M., Pantano, A., \& Rudlin, J. (2015). Inspection Of Additive-Manufactured Layered Components. Ultrasonics, 62, 292-298.

Chauveau, D. (2018). Review Of NDT And Process Monitoring Techniques Usable To Produce High-Quality Parts By Welding Or Additive Manufacturing. Welding İn The World, 62(5), 1097-1118.

Diamanti, K., \& Soutis, C. (2010). Structural Health Monitoring Techniques For Aircraft Composite Structures. Progress İn Aerospace Sciences, 46(8), 342-352.

Drury, C. G., \& Watson, J. (2002). Good Practices İn Visual İnspection. Human Factors İn Aviation Maintenance-Phase Nine, Progress Report, FAA/Human Factors İn Aviation Maintenance.@ URL: Http://Hfskyway. Faa. Gov.

Duarte, D., Marado, B., Nogueira, J., Serrano, B., Infante, V., \& Moleiro, F. (2016). An Overview On How Failure Analysis Contributes To Flight Safety In The Portuguese Air Force. Engineering Failure Analysis, 65, 86-101.

Durmuş, H., \& Baygut, A. (2018). Soğuk Dövme Yöntemi İle Üretilen Bağlantı Elemanındaki Kılcal Kafa-Kılcal Vida Diş Yüzey Çatlaklarının Girdap Akımları Metodu İle Analizi. Sinop Üniversitesi Fen Bilimleri Dergisi, 4(1), 28-36.

Dwivedi, S. K., Vishwakarma, M., \& Soni, A. (2018). Advances And Researches On Non Destructive Testing: A Review. Materials Today: Proceedings, 5(2), 3690-3698.

Emerson, R. N., Pollock, D. G., Kainz, J. A., Fridley, K. J., Mclean, D., \& Ross, R. J. (1998, August). Nondestructive Evaluation Techniques For Timber Bridges. In $\mathrm{V}$ World Conference On Timber Engineering. Montreux, Switzerland (Vol. 1, Pp. 670-677).

Fathi-Haftshejani, P., \& Honarvar, F. (2019). Nondestructive Evaluation Of Clad Rods By Inversion Of Acoustic Scattering Data. Journal Of Nondestructive Evaluation, 38(3), 1-9.

Fotouhi, S., Pashmforoush, F., Bodaghi, M., \& Fotouhi, M. (2021). Autonomous Damage Recognition İn Visual Inspection Of Laminated Composite Structures Using Deep Learning. Composite Structures.

Garcia Marquez, F. P., \& Gomez Munoz, C. Q. (2020). A New Approach For Fault Detection, Location And Diagnosis By Ultrasonic Testing. Energies, 13(5), 1192.

Gärtner, S., Krause, H. J., Wolters, N., Lomparski, D., Wolf, W., Schubert, J., ... \& Allweins, K. (2002). Non-Destructive
Evaluation Of Aircraft Structures With A Multiplexed HTS Rf SQUID Magnetometer Array. Physica C: Superconductivity, 372, 287-290.

Gholizadeh, S. (2016). A Review Of Non-Destructive Testing Methods Of Composite Materials. Procedia Structural Integrity, 1, 50-57.

Goranson, U. G. (1983). Elements Of Damage Tolerance Verification. In Proceeding Of The 12th International Committee On Aeronautical Fatigue Symposium (Pp. 1-8).

Gönül, E., \& Bayraktaroğlu, B. (2015). İş Güvenliğinde Tahribatsız Muayenenin Önemi.

Gönül, E., \& Bayraktaroğlu, B. (2018). İşletmede Kullanılan İş Ekipmanlarının Yorulma Durumlarının Tahribatsız Muayene İle Belirlenmesi.

Gövce, M. S. (2005). Uçak Bakımında Korozyon Analizi (Master's Thesis, Anadolu Üniversitesi).

Grimm, T., Wiora, G., \& Witt, G. (2015). Characterization Of Typical Surface Effects İn Additive Manufacturing With Confocal Microscopy. Surface Topography: Metrology And Properties, 3(1), 014001.

Guirong, X., Xuesong, G., Yuliang, Q., \& Yan, G. (2015). Analysis And İnnovation For Penetrant Testing For Airplane Parts. Procedia Engineering, 99, 1438-1442.

Gül, H. (2019). Seyyar Yangın Söndürme Cihazlarının İmalatında Uygulanan İdeal Gaz Altı Alın Kaynak Prosedürü Değerlerinin Tespiti (Master's Thesis, Namık Kemal Üniversitesi).

Günay, H. (2008). Girdap Akımları İle Malzeme Muayenesinde Malzeme Ayırımı, Yüzeysel Çatlak Kontrolü, Boru, Mil Ve Bilet Kontrolü Ve Döner Bobinli Test Sistemlerinde Muayeneye Etki Eden Parametrelerin Deneysel Olarak Optimizasyonu (Doctoral Dissertation, DEÜ Fen Bilimleri Enstitüsü).

Gürsel, A. (2013). Petrol Borularının Kaynaklarında Radyografik Muayene Yönteminin Hata Tespit Kabiliyeti. İleri Teknoloji Bilimleri Dergisi, 2(1), 55-65.

Habibpour-Ledari, A., \& Honarvar, F. (2018). Three Dimensional Characterization Of Defects By Ultrasonic Time-Of-Flight Diffraction (Tofd) Technique. Journal Of Nondestructive Evaluation, 37(1), 1-11.

Ippolito, R., Iuliano, L., \& Gatto, A. (1995). Benchmarking Of Rapid Prototyping Techniques İn Terms Of Dimensional Accuracy And Surface Finish. CIRP Annals, 44(1), 157-160.

Jewett, J. W., \& Serway, R. (2008). Physics For Scientists And Engineers With Modern Physics. Vectors, 1, 2.

Kafalı, H. (2004). Uçaklarda Sandviç Kompozitlere Uygulanan Tahribatsız Muayene Yöntemleri (Master's Thesis, Anadolu Üniversitesi).

Kalinichenko, A., Sosnin, E., Avdeev, S., Kalinichenko, N., \& Lobanova, I. S. (2019). Fluorescent Penetrant Testing By Means Of Excilamps. In Materials Science Forum (Vol. 942, Pp. 131-140). Trans Tech Publications Ltd.

Kayrak, M. A. (2012). UÇAK BAKIMINDA DARBE HASARININ TAHRİBTSIZ KONTROLÜ. Engineer \& The Machinery Magazine, (629).

Kılıç, O. (2019). Marmaray Demiryolu Hattında Ray Kusurlarının Ultrasonik Yöntemle İncelenmesi Ve Ray Kusurlarının Hattın Hangi Kısımlarında Yoğunlaştığının Tespiti (Doctoral Dissertation, Marmara Universitesi (Turkey)).

Kujawińska, A., \& Vogt, K. (2015). Human Factors İn Visual Quality Control. Management And Production Engineering Review, 6. 
Lu, Q. Y., \& Wong, C. H. (2017). Applications Of NonDestructive Testing Techniques For Post-Process Control Of Additively Manufactured Parts. Virtual And Physical Prototyping, 12(4), 301-321.

Ma, H. W., Zhang, X. H., \& Wei, J. (2002). Research On An Ultrasonic NDT System For Complex Surface Parts. Journal Of Materials Processing Technology, 129(1-3), 667-670.

Mahoon, A. (1988). The Role Of Non-Destructive Testing İn The Airworthiness Certification Of Civil Aircraft Composite Structures. Composites, 19(3), 229-235.

Manikandan, K. R., Sivagurunathan, P. A., Ananthan, S. S., Moshi, A. A. M., \& Bharathi, S. S. (2020). Study On The İnfluence Of Temperature And Vibration On İndications Of Liquid Penetrant Testing Of A516 Low Carbon Steel. Materials Today: Proceedings.

Matzkanin, G. A. (2006). Selecting A Nondestructive Testing Method: Visual İnspection. Advanced Materials, Manufacturing And Testing Information Analysis Center, 1(3), 7-10.

Melloy, B. J., Harris, J. M., \& Gramopadhye, A. K. (2000). Predicting The Accuracy Of Visual Search Performance İn The Structural İnspection Of Aircraft. International Journal Of İndustrial Ergonomics, 26(2), 277-283.

Migoun, N. P., \& Delenkovsky, N. V. (2008, October). The Ways Of Penetrant Testing Applicability For Rough Surfaces. In Proceedings Of 17 th World Conf. On NDT, Shanghai, China (Pp. 25-28).

Mouritz, A. P., Townsend, C., \& Khan, M. S. (2000). NonDestructive Detection Of Fatigue Damage In Thick Composites By Pulse-Echo Ultrasonics. Composites Science And Technology, 60(1), 23-32.

Nesvijski, E. G. (2000). Some Aspects Of Ultrasonic Testing Of Composites. Composite Structures, 48(1-3), 151-155.

Novák, A., Sedláčková, A. N., Bugaj, M., Kandera, B., \& Lusiak, T. (2020). Use Of Unmanned Aerial Vehicles İn Aircraft Maintenance. Transportation Research Procedia, 51, $160-170$

Okan, K. A. R. A., Erdal, H., \& Çelik, H. H. (2017). Tahribatsız Test Yöntemleri: Karşılaştırmalı Bir Derleme Çalışması. Marmara Fen Bilimleri Dergisi, 29(3), 82-93.

Omelić, M., \& Hrman, D. (2006). Measurements Of UV Radiation During NDT Inspection. In 9th European Conference On NDT, Proceedings BB 103-CD.

Öktem, H. F. (2002). Ultrasonık Tahrıbatsız Muayene Teknıgının Sonlu Elemanlar Yöntemı Ile Incelenmesı (Doctoral Dissertation, Doktora Tezi, Dokuz Eylül Üniversitesi Fen Bilimleri Enstitüsü, İzmir).

Özkan, E. (2019). Kaynak Sonrası S355J2N Yapı Çeliğinde Oluşan Gerilmeleri Gidermek İçin Uygulanan Isıl İşlemin Etkilerinin Tahribatlı-Tahribatsız Muayene Yöntemleriyle Belirlenmesi (Master's Thesis, Namik Kemal Üniversitesi).

Papa, U., \& Ponte, S. (2018). Preliminary Design Of An Unmanned Aircraft System For Aircraft General Visual İnspection. Electronics, 7(12), 435.

Parida, N. (2009). Non Destructive Testing And Evaluation

Prassianakis, I. N., \& Prassianakis, N. I. (2004). Ultrasonic Testing Of Non-Metallic Materials: Concrete And Marble. Theoretical And Applied Fracture Mechanics, 42(2), 191198.

Raj, B., Jayakumar, T., \& Thavasimuthu, M. (2002). Practical Non-Destructive Testing. Woodhead Publishing.

Robini, M. C., Labruyere, J. P., \& Magnin, I. E. (2006). Radiographic İnspection Of Thick Metal Components, Part
I: Fitting The Standard Linear İmage Formation Model. In 2006 IEEE Nuclear Science Symposium Conference Record (Vol. 2, Pp. 964-968). IEEE.

Schmerr, L. W. (2016). Fundamentals Of Ultrasonic Nondestructive Evaluation. New York, NY, USA:: Springer.

Seçim, C. (2011). 'Tahribatsız Muayene Yöntemleri Ve Uygulama Alanları', Mustafa Kemal Üniversitesi Fen Bilimleri Enstitüsü, Hatay, 2011.

See, J. E. (2015). Visual İnspection Reliability For Precision Manufactured Parts. Human Factors, 57(8), 1427-1442.

Sezgin, H. S., Muftuler, F. Z. B., Ichedef, C., Kilcar, A. Y., Teksoz, S., Unak, P., \& Harmansah, C. (2017). A New Approach To Liquid Penetrant İnspection: Radiolabeled Qdots. Journal Of Radioanalytical And Nuclear Chemistry, 313(2), 291-297.

Shakibi, B., Honarvar, F., Moles, M. D. C., Caldwell, J., \& Sinclair, A. N. (2012). Resolution Enhancement Of Ultrasonic Defect Signals For Crack Sizing. NDT \& E International, 52, 37-50.

Shull, P. J. (2002). Nondestructive Evaluation: Theory, Techniques, And Applications. CRC Press.

Stancu, C., Grigore, E., Storan, D., \& Dumitru, A. (2011). "Integration Of Nondestructive Testıng In Aircrafts Mentenance".

Suhaila, Y., Rafidah, A., Ariffin, N. H., Arshad, A., Ismail, S. A., Bakar, F. A. A., \& Ibrahim, M. (2014). Development Time In Liquid Penetration Testing For Metal Butt Joint. In Applied Mechanics And Materials (Vol. 465, Pp. 11091113). Trans Tech Publications Ltd.

Taheri, H., Kilpatrick, M., Norvalls, M., Harper, W. J., Koester, L. W., Bigelow, T., \& Bond, L. J. (2019). Investigation Of Nondestructive Testing Methods For Friction Stir Welding. Metals, 9(6), 624.

Towsyfyan, H., Biguri, A., Boardman, R., \& Blumensath, T. (2020). Successes And Challenges İn Non-Destructive Testing Of Aircraft Composite Structures. Chinese Journal Of Aeronautics, 33(3), 771-791.

Tuğrul, A. B., Baydoğan, N., Altınsoy, N., Dizar, D., \& Yağcı, E. (2008). Otomotiv Parçalarının Radyografik İncelenmesi.

Türker, M., Güven, E. A., \& Ertürk, A. T. (2011). Ultrasonik Yöntem İle Tahribatsı Malzeme Muayenesi. Metal Dünyas1, 222, 108-115.

Üllen, N. B., \& Baba, G., (2020), 'Çeşitli Sicak Dövme Kalıplarının Hasar Mekanizmalarının İncelenmesi' 2nd International Eurasian Conference On Science, Engineering And Technology, Ocak, 2020.

Üner, Ü. (2011). Mekanik Boya Sökme İşleminin Al 2024 T6 Alaşımının Yorulma Özelliklerine Etkisi (Master's Thesis, Eskişehir Osmangazi Üniversitesi/Fen Bilimleri Enstitüsü).

Yağc1, T., Çidem, A., \& Durmuş, H. (2018). Geçmişten Günümüze Tahribatsız Muayene Yöntemleri. Soma Meslek Yüksekokulu Teknik Bilimler Dergisi, 3(27), 49-61.

Yetiştiren, H., Zeren, A., \& Feyzullahoğlu, E. (2007). Taşıma Tekniği Ekipmanlarının Bakımında Kullanılan Tahribatsız Muayene Yöntemleri. Mühendis Ve Makina, 48(571), 17-24.

Yılmaz, H. (2014). Ray Kusurlarının Örnek Hat Üzerinde Ultrasonik Yöntemle İncelenmesi Ve Ray Gerilmelerinin Belirlenmesi (Doctoral Dissertation, Fen Bilimleri Enstitüsü).

Zorbacı, B. (2011). Uçak Bakım İşletmesinde İyileştirme Öneri Ve Uygulamaları (Master's Thesis, Kocaeli Universitesi, Fen Bilimleri Enstitusu). 